\title{
La importancia de la \\ perspectiva histórica y de los modelos en la enseñanza de la física
}

\author{
Juan Manuel Perea \\ Programa Matemáticas y Física
}

Probablemente uno de los grandes vacíos pedagógicos de los programas curriculares de Física, tanto a nivel de educación media como universitaria, es la falta de perspectiva histórica que nos permita relativizar sanamente la concepción de realidad y de verdad. Cuando se piensa o enseña una idea o concepto tomada como una verdad absoluta situada en un determinado momento histórico estamos asumiendo un papel terminal a la ciencia.

La ciencia es ante todo un sistema inacabado en permanente elaboración y aniquilación: se construyen nuevas teorías en detrimento de las anteriores que no pueden competir en poder explicativo (por ejemplo la teoría ondulatoria de la luz de Huygens a cambio de la teoría corpuscular de Newton); con las nuevas teorías nacen nuevos conceptos y surgen nuevas realidades.

Estas nuevas realidades no se refieren desde luego, a los datos perceptuales como tales. Ilustramos esto con el siguiente ejemplo: Hace varios miles de años el cielo en la noche tenía aproximadamente la misma apariencia que la que hoy tiene. En otras palabras, las retinas de nuestros antepasados eran afectadas por lo que hoy llamamos "ondas electromagnéticas" de la misma forma como son afectadas las nuestras al mirar hacia el cielo en una noche estrellada. Pero la realidad de nuestros ancestros remo- tos era bien diferente. Loque ellos observaban eran las hogueras de los nómadas de la inmensidad, que en la noche, al igual que ellos, dormían alrededor del fuego protector. Poco después esos mismos datos perceptuales eran pequeños huecos en la gran bóveda celeste que dejaban pasar la luz inmensa de Dios. Más tarde fueron inmensas bolas de fuego suspendidas de las grandes esferas de cristal que conformaban un sistema concéntrico en el cual la tierra era el centro. Posteriormente fueron grandes masas incandescentes que gravitaban según las leyes de Kepler. Hoy son la luz de sistemas solares muy lejanos; algunos de ellos extintos hace muchos millones de años. En este sentido, puede decirse incluso, que lo que observamos es el pasado de sistemas solares situados en espacio-tiempos diferentes.

Por lo general la física se fundamenta en modelos para estudiar los fenómenos naturales. La realidad es la realidad a través de un modelo. Cuando decimos o enseñamos que el átomo es como un sistema solar en miniatura, cstamos estableciendo una relación de isomorfismo en la que el núcleo juega el papel del sol y los electrones juegan el papel de planetas. En esta modelación del átomo partimos del supuesto de que conocemos bien la estructura y el funcionamiento del sistema solar (por lo menos en cuanto a los movimientos gravitatorios que se asemejan a los de los electrones cuando aplicamos las 
leyes de la mecánica) y pretendemos extraer buenos beneficios de este conocimiento aproximándonos a algo desconocido pero de lo cual suponemos que son "iguales". Quien entiende un modelo entiende que esta igualdad es muy relativa: cuando se habla del átomo como sistema solar muy pequeño, quien entiende el modelo no preguntará por los satélites de los electrones, ni mucho menos si en uno de ellos hay atmósfera y vida.

Pero el estudiante normalmente cree que la realidad es como se dice que es en los libros; pocas veces es consciente de que lo que estudia en los libros son diversos modelos que algún día pueden ser superados por otros. Mucho menos es consciente de que esos modelos son construcciones que hacen los científicos y que cumplen un papel en determinada época de acuerdo al desarrollo de las teorías.

Los modelos no sólo son una forma de expresar cierta realidad sino que también permiten ampliar los horizontes de esa realidad. Por ejemplo, la tabla periódica de Mendeleiev es un modelo que organiza los elementos y sus propiedades conocidas y además predice la existencia de otros y además señala errores de observación para algunos elementos que ya se habian descrito.

Pero la tabla que hoy conocemos no es la que Mendeleiev presentó ante su comunidad científica. Esta tabla, como todos los modelos, ha evolucionado. Por otro lado Mendeleiev muy probablemente no hubiera

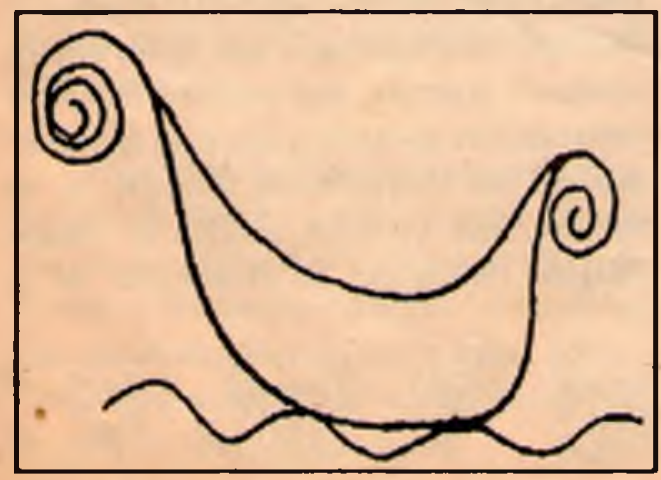

podido elaborar la tabla si Dodereiner y Newlands no hubiesen realizado intentos anteriores en el mismo sentido. Estos intentos contribuyeron para que se diera algo muy común en la ciencia y es que dos científicos (Mendeleiev y Meyer), independientemente, llegaron a modelos muy similares.

Pero no solamente los científicos miran la realidad con modelos (muy elaborados), todo ser humano en forma natural trata de construir su modelo (elemental) para explicar cierta realidad. Por ejemplo, cuando pedimos a nuestros alumnos una explicación acerca de la forma como opera una palanca es frecuente tener respuestascomo: "unapalanca es como un super-codo".

Aqui, al profesor le preocupa que este modelo no se ajuste totalmente a la realidad o que no se formule en términos cuantitativos y en forma de ecuación matemática y entonces hace la correspondiente corrección imponiendo el modelo del libro. El modelo de Mendeleiev tampoco era totalmente ajustado a la realidad y seguramente el actual sufrirá cambios o reinterpretaciones según su evolución. La estrategia pedagógica está entonces en dar las condiciones para que los modelos ofrecidos pr los alumnos evolucionen. La evolución de sus modelos no solo les permitirá entender la visión actualizada del modelo sino que además le permitirá percibir ese carácter evolutivo de la construcción científica. En otras palabras es más importante que el estudiante entienda la estructura del conocimiento científico y la forma como se construye y no que se limite únicamente a memorizar los resultados logrados en un determinado momento de la ciencia.

En conclusión, una adecuada metodología para la enseñanza de la física, y en general de la ciencia, debe pretender mostrar la dinámica de la física, su estructura y evolución histórica y no por el contrario transmitir al estudiante uria imagen de la física como una ciencia terminal acabada. 